\title{
Topically Applied Minoxidil in Baldness
}

\author{
Ervin Novak, M.D., Thomas J. Franz, M.D., John T. Headington, M.D., \\ and Ronald C. Wester, Ph.D.
}

From the Upjohn Company, Kalamazoo, Michigan, School of Medicine, University of Washington, Seattle,

Washington, Medical School, University of Michigan, Ann Arbor, Michigan, and School of Medicine and School of Pharmacy, University of California, San Francisco, California

Minoxidil, an orally administered, peripheral vasodilator used to treat hypertension, causes hypertrichosis in more than $80 \%$ of users. The drug reduces elevated blood pressure by decreasing peripheral vascular resistance. Chemically, minoxidil is 2,4-diamino-6-piperidinopyrimidine-3-oxide; it is soluble in water to the extent of approximately $2 \mathrm{mg} / \mathrm{ml}$, is more readily soluble in propylene glycol or ethanol, and is nearly insoluble in acetone, chloroform, or ethyl acetate. Following oral administration of minoxidil and in association with the reduction in peripheral vascular resistance, cardiac output is augmented, salt and water are retained, and plasma renin activity rises. ${ }^{1,2}$

When taken orally, minoxidil is at least $90 \%$ absorbed from the human gastrointestinal tract. After one 5-mg tablet of minoxidil, blood levels of the parent drug reach a maximum of $156.6 \mathrm{ng} / \mathrm{ml}$ within the first hour and decline rapidly thereafter to 1.5 $\mathrm{ng} / \mathrm{ml}$ within 24 hours (Table 1). The average plasma half-life in humans is 4.2 hours for the combination of parent drug and its metabolites. About $90 \%$ of administered drug is metabolized, predominantly by conjugation with glucuronic acid, ${ }^{3-5}$ and parent drug and metabolites are principally excreted in the urine. Minoxidil does not bind to plasma proteins, and its renal clearance corresponds to the glomerular filtration rate. In the absence of functional renal tissue, minox-

Address for correspondence: E. Novak, M.D., The Upjohn Company, 7254-24-2, 301 Henrietta Street, Kalamazoo, MI 49001. idil and its metabolites can be removed by hemodialysis.

Fluid retention and hypertrichosis are the most commonly occurring side effects of minoxidil. Hair regrowth in a patient with male pattern baldness was described in a case report of a hypertensive patient treated twice daily with $20 \mathrm{mg}$ oral minoxidil. ${ }^{6}$ The extensive hair regrowth continued after 10 months of therapy. New and increased hair growth as a side effect was also detected in an early clinical study involving five of eight patients on oral minoxidil therapy for 2 months. ${ }^{7}$ Zappacosta ${ }^{8}$ reported reversal of baldness in a patient on minoxidil for the treatment of hypertension.

After the third week of therapy with oral minoxidil, hypertrichosis usually appears between the eyebrows and the hair line, in the malar and temporal areas, on the backs of the arms, on the shoulders, and on the legs. Hair growth has been noted at all dose levels, although it appears later and is less marked after the smaller doses of $10 \mathrm{mg}$ or less per day. New hair growth ceases abruptly when minoxidil therapy is discontinued, but the patient's appearance does not return to normal for several months. Normal hormonal assays were recorded in 50 patients who received minoxidil for 1 year or longer, ${ }^{7,9}$ and we do not believe that excessive hair growth is a result of an endocrine abnormality.

\section{Overview of Efficacy and Safety}

Dermal acute toxicity studies in rats have shown that minoxidil is not toxic when applied $10 \mathrm{mg} / \mathrm{rat} /$ day and is slightly toxic at $30 \mathrm{mg} / \mathrm{rat} /$ day and 60 $\mathrm{mg} / \mathrm{rat} /$ day. While no gross or microscopic lesions were found in the rat skin, the pharmacologic effects included dose-related decreases in hemoglobin, decreased erythrocyte counts, decreases in serum sodium and chloride levels, and increases in serum cholesterol and heart and liver weight. 
TABte 1. Mean Minoxidil Blood Levels from 20 Patients After Ingestion of One 5-mg Tablet

\begin{tabular}{|c|c|c|c|c|c|c|c|c|}
\hline Hours & 0.0 & 1.0 & 2.5 & 4.0 & 7.0 & 11.0 & 16.0 & 24.0 \\
\hline Mean concentration of minoxidil $(\mathrm{ng} / \mathrm{ml})$ & 6.65 & 156.5 & 71.0 & 54.4 & 23.3 & 7.8 & 5.7 & 1.5 \\
\hline
\end{tabular}

We are conducting the clinical research program for topical minoxidil slowly and with caution because of the potent action of the systemic formulation of minoxidil on the cardiovascular system in hypertensive patients. Initially, three 14-week studies involved daily bilateral applications of $1 \%, 3 \%$, or $5 \%$ minoxidil to circular areas $2 \mathrm{~cm}$ in diameter on the scalps of patients with male pattern baldness. As expected, no systemic side effects were observed. There was some evidence of hair growth stimulation, appreciably delayed and variable in occurrence among patients.

Long-term clinical studies of 6-12 months were started in 1980 and 1981. Since then, several clinical studies have been completed and new ones started. For example, in one open-label study, we evaluated the effectiveness of twice-daily unoccluded applications of $5 \%$ minoxidil in men and women with alopecia areata and alopecia androgenetica. Therapy was scheduled for 6 months in alopecia areata and for 1 year in pattern baldness. Stimulation of hair growth ranged from minimal early evidence to appreciable restoration toward typical terminal scalp hair. It took 3-8 months to obtain the more definitive evidence of stimulated hair growth. Other investigators who used a topically applied solution of $1 \%$ minoxidil in three patients with alopecia areata unresponsive to conventional treatments found local hair regrowth in the area of application within 4-6 weeks in two of the patients. ${ }^{10}$

Fenton and Wilkinson ${ }^{11}$ induced hair growth in 22 of $30(80.8 \%)$ patients with alopecia areata after 6 months of twice-daily topical applications of $1 \%$ minoxidil lotion or ointment. Sixteen of these patients grew acceptable terminal hair.

In a double-blind study, Headington and Novak ${ }^{12}$ treated 21 healthy men with pattern baldness with twice-daily topical applications of $1 \%$ or $5 \%$ minoxidil or the vehicle for minoxidil (water-propylene glycolalcohol). The shortest and longest hairs measured were recorded for each treatment site through study week 25 (Table 2). Medications were applied only for 15.7 weeks ( 110 successive days), and no medication was applied during weeks 16-25. Results were expressed as the difference between an individual's minimum and maximum lengths of hair at baseline and at each evaluation period. A minimal increase in mean hair length was seen in all treatment groups, including the placebo group, between weeks 3-9 and at week 25 . There were no statistically significant differences among the groups in the hair growth during the 12-week medication period.

After 15.7 weeks of treatment in this study, clinical and statistical evaluations of the blood chemistries, $\mathrm{CBC}$, urinalysis, and EKG were similar for subjects receiving the $1 \%$ or $5 \%$ solutions of minoxidil and those receiving the placebo vehicle, nor was there a difference between mean pre- and postmedication values in blood pressure, pulse rate, and body weights in these subjects. Mild stinging, burning, itching, and erythema were noted only after the evaluation at week 2 in 11 of 21 subjects ( 2 receiving 1\% minoxidil, 4 receiving $5 \%$ minoxidil, and 5 receiving the vehicle). These effects were thought to be due to the vehicle.

\section{Absorption and Excretion After Topical Minoxidil}

In animal and human topical absorption studies, we have used $1 \%, 3 \%$, and $5 \%$ minoxidil in a propylene glycol-ethanol-water vehicle. When vehicles containing propylene glycol-alcohol-water

TABle 2. Mean Hair Length $(\mathrm{mm})$ in Topically Treated Area of Scalp in 21 Men with Pattern Baldness

\begin{tabular}{|c|c|c|c|c|c|c|c|c|c|}
\hline \multirow[b]{2}{*}{ Week } & \multicolumn{3}{|c|}{$1 \%$ Minoxidil } & \multicolumn{3}{|c|}{$5 \%$ Minoxidil } & \multicolumn{3}{|c|}{ Placebo } \\
\hline & $\mathrm{N}$ & Min & Max & $N$ & Min & Max & $\mathrm{N}$ & Min & Max \\
\hline 0 & 7 & 1.0 & 1.1 & 7 & 1.0 & 1.1 & 7 & 1.1 & 1.9 \\
\hline 3 & 7 & 1.0 & 2.4 & 7 & 1.4 & 2.6 & 7 & 1.3 & 2.6 \\
\hline 4 & 7 & 1.4 & 2.0 & 7 & 1.1 & 1.9 & 7 & 1.7 & 2.4 \\
\hline 5 & 7 & 1.0 & 1.1 & 7 & 1.0 & 1.1 & 7 & 1.0 & 1.9 \\
\hline 9 & 5 & 1.4 & 2.8 & 6 & 2.2 & 3.3 & 6 & 1.3 & 2.0 \\
\hline 13 & 5 & 2.4 & 2.4 & 7 & 2.7 & 2.7 & 5 & 1.4 & 2.0 \\
\hline $25^{\circ}$ & 3 & 20.0 & 49.7 & 6 & 43.3 & 48.3 & 4 & 22.5 & 26.3 \\
\hline
\end{tabular}


TABLE 3. Percutaneous Absorption of Topical ${ }^{14} \mathrm{C}$-Minoxidil in the Rat and Monkey

\begin{tabular}{lccll}
\hline Animal & $\mathrm{N}$ & $\begin{array}{c}\text { Drug } \\
\text { Concentration }\end{array}$ & \multicolumn{1}{c}{$\begin{array}{c}\text { Regimen } \\
\text { of Applied } \\
\text { Dose Absorbed* }\end{array}$} \\
\hline Rat & 5 & $1 \%$ & $\begin{array}{l}\text { Single application } \\
\text { Single application after } 9 \text { daily applications }\end{array}$ & $\begin{array}{l}18.1 \% \\
35.6 \%\end{array}$ \\
Rat & 5 & $4 \%$ & $\begin{array}{l}\text { Single application } \\
\text { Single application after } 9 \text { daily applications }\end{array}$ & $26.9 \%$ \\
Monkey & 3 & $1 \%$ & Single application & $17.2 \%$ \\
Monkey & 4 & $4 \%$ & Single application & $5.6 \%$ \\
\hline
\end{tabular}

- Derived from the percentage of applied dose of labeled drug excreted in urine and stool.

were used, the in vitro transport data over 72 hours showed a cumulative penetration of $3.0 \mathrm{mg}, 3.7 \mathrm{mg}$, and $4.0 \mathrm{mg}$ of drug from the $1 \%, 3 \%$, and $5 \%$ minoxidil solutions, respectively. The extent of percutaneous absorption in the rat and monkey, based upon the percentage of the applied dose of ${ }^{14} \mathrm{C}$ minoxidil excreted in the urine and stool, is shown in Table 3. In the rat and monkey, the skin of the application sites retained $30-78 \%$ of the applied dose of ${ }^{14} \mathrm{C}$-minoxidil.

In ongoing clinical trials with topical minoxidil in patients with alopecia areata and alopecia androgenetica or both, we are using applications of $1 \%, 3 \%$, and $5 \%$ minoxidil solutions once daily with or without overnight occlusion. After therapy ranging from a few months to 1 year in 150 patients, single-point and variable time values of serum minoxidil in six patients so tested at 2, 4, and 8 weeks tended to range from nondetectable levels (radioimmunoassay sensitivity of $1.4 \mathrm{ng} / \mathrm{ml}$ ) to a maximum of $6.2 \mathrm{ng} / \mathrm{ml}$. In a double-blind study of 21 men with pattern baldness, ${ }^{12}$ a radioimmunoassay with a sensitivity of $1.4 \mathrm{ng} / \mathrm{ml}$ showed no consistency or trend in minoxidil serum levels (Table 4). The highest levels of minoxidil $(6.2$ $\mathrm{ng} / \mathrm{ml}$ ) occurred in the $5 \%$ minoxidil group at week 2 . One subject in the $1 \%$ minoxidil group had a serum level of $2.3 \mathrm{ng} / \mathrm{ml}$ minoxidil at week 2 .

In a percutaneous absorption/excretion study, $1 \%$ or $5 \%$ solutions of ${ }^{14} \mathrm{C}$-minoxidil were applied topically to the scalps of 12 healthy men. At either dose, minoxidil was poorly absorbed through the skin. The mean recovery of the applied doses in the urine was less than 4\% (Table 5). A fecal analysis was done in six of these volunteers and no radioactivity was

TABle 4. Minoxidil Serum Levels* $(\mathrm{ng} / \mathrm{ml})$ in 21 Men with Pattern Baldness

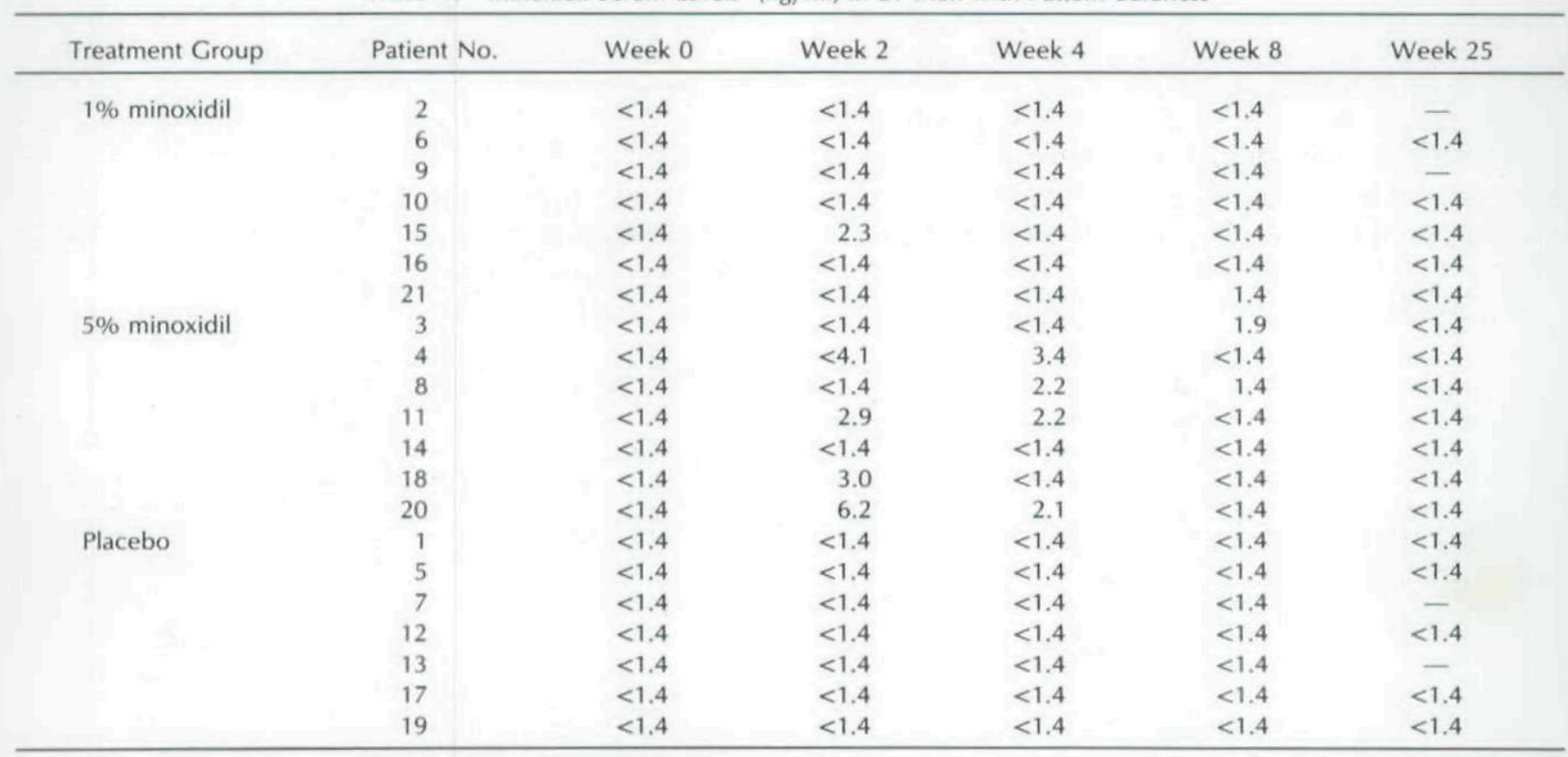

\footnotetext{
- Radioimmunoassay (sensitivity of $1.4 \mathrm{ng} / \mathrm{ml}$ ) of serum drawn in morning before breakfast, about 10-12 hours after topical application
} of treatment solution. 
TABLE 5. Urinary Excretion of ${ }^{14} \mathrm{C}$-Minoxidil (\% of Dose) After Topical Application to Normal Subjects

\begin{tabular}{|c|c|c|c|c|c|}
\hline \multicolumn{3}{|c|}{$1 \%$ Minoxidil } & \multicolumn{3}{|c|}{$5 \%$ Minoxidil } \\
\hline Subject & $\begin{array}{c}\text { Application } 1 \\
\text { (Day 1) }\end{array}$ & $\begin{array}{c}\text { Application } 2 \\
\text { (Day 9) }\end{array}$ & Subject & $\begin{array}{c}\text { Application } 1 \\
\text { (Day 1) }\end{array}$ & $\begin{array}{c}\text { Application } 2 \\
\text { (Day 9) }\end{array}$ \\
\hline 1 & 3.91 & 2.60 & 2 & 3.06 & 4.47 \\
\hline 4 & 4.26 & 3.63 & 3 & 2.76 & 1.05 \\
\hline 5 & 2.82 & 1.05 & 6 & 0.89 & 0.27 \\
\hline 7 & 9.33 & 2.38 & 8 & 1.65 & 0.71 \\
\hline 9 & 0.91 & 1.25 & 10 & 1.01 & 0.80 \\
\hline 12 & 2.00 & 3.11 & 11 & 1.62 & 2.10 \\
\hline Group mean $\pm S D$ & $3.87 \pm 2.94$ & $2.34 \pm 1.02$ & & $1.83 \pm 0.90$ & $1.57 \pm 1.55$ \\
\hline
\end{tabular}

detected. A mean of $43-45 \%$ of the $1 \%$ and $5 \%$ applications of radioactive minoxidil was recovered from the surface of the skin (Table 6). The total recovery of ${ }^{14} \mathrm{C}$-minoxidil in this study ranged from $42.9 \%$ to $47.2 \%$ for either dose at any of the test periods. We presume that the remaining material was lost from the surface of the skin to the environment. We evaluated the possibility that a portion of applied minoxidil is bound within the skin and slowly released to the systemic circulation, where it might be below the limits of detection used in this study. Biopsied tissue of the scalp from five patients 24 hours after the second treatment showed radioactivity of $0.0001 \%$ to $.0015 \%$.

\section{Effect of Topical Minoxidil on Blood Flow of the Scalp}

Burton and co-workers ${ }^{13,14}$ postulated increased cutaneous perfusion with potent peripheral vasodilators. It has been suspected for a long time that localized hypertrichosis is associated with increased cutaneous blood flow in some cutaneous inflammatory conditions as well as with arteriovenous aneurysm. ${ }^{15-17}$
In another double-blind study, we tested $0 \%, 1 \%$, $3 \%$, and $5 \%$ randomly assigned solutions of minoxidil on the balding scalps of 16 human volunteers. On 2 consecutive days, an $0.25 \mathrm{ml}$ volume of the formulations was uniformly spread over $100 \mathrm{~cm}^{2}$ of the bald scalp. After 15 minutes, cutaneous blood flow was recorded continuously for 40-60 minutes, then intermittently for 4 hours. A single microcirculatory flow parameter was measured by laser Doppler velocimetry (LDV), ${ }^{18-20}$ and changes in microcirculatory blood volume were measured by photopulse plethysmography (PPG)..$^{21,22}$

The $5 \%$ minoxidil solution increased blood flow when compared with the other treatments. As shown by LDV, on day 1 (Fig. 1) there was a statistically significant increase $(p=0.0001)$ in mean blood flow within 15 minutes of application; that flow was maintained at least through 1 hour. On day 2 (Fig. 2), blood flow stimulation increased $(p=0.0001)$ threefold within 15 minutes of application and remained that way for about 1 hour. With the photopulse plethysmography technique, the mean blood perfusion response was statistically significant $(p=0.01)$ only for application of the $5 \%$ minoxidil solution on day 2.

TABle 6. Recovery of ${ }^{14} \mathrm{C}$-Minoxidil ( $\%$ of Dose) From Surface of the Skin in Normal Subjects

\begin{tabular}{|c|c|c|c|c|c|}
\hline \multicolumn{3}{|c|}{$1 \%$ Minoxidil } & \multicolumn{3}{|c|}{$5 \%$ Minoxidil } \\
\hline Subject & $\begin{array}{c}\text { Application } 1 \\
\text { (Day 1) }\end{array}$ & $\begin{array}{c}\text { Application } 2 \\
\text { (Day 9) }\end{array}$ & Subject & $\begin{array}{c}\text { Application } 1 \\
\text { (Day 1) }\end{array}$ & $\begin{array}{c}\text { Application } 2 \\
\text { (Day 9) }\end{array}$ \\
\hline 1 & 37.1 & 45.9 & 2 & 57.3 & 63.4 \\
\hline 4 & 37.7 & 45.9 & 3 & 23.5 & $2.4^{*}$ \\
\hline 5 & 27.2 & 46.1 & 6 & 37.7 & 28.9 \\
\hline 7 & 69.9 & 44.8 & 8 & 40.3 & 53.9 \\
\hline 9 & 27.9 & 24.2 & 10 & 56.9 & 44.2 \\
\hline 12 & 60.2 & 58.4 & 11 & 54.1 & 54.9 \\
\hline Group mean $\pm S D$ & $43.4 \pm 17.7$ & $44.2 \pm 11.1$ & & $45.0 \pm 13.5$ & $41.3 \pm 22.4$ \\
\hline
\end{tabular}

* Subject used hair drier several hours after treatment was applied. 


\section{Histopathologic Findings in the Scalp After Topical Applications of Minoxidil}

In a double-blind study by Headington and Novak, ${ }^{12}$ a $1 \%$ or $5 \%$ minoxidil solution or placebo was applied twice daily to three groups of seven healthy men with pattern bladness. In all 21 patients, a 4-mm Baker disposable punch was used to obtain a biopsy from the vertex or from the parietal areas of the scalp pretreatment and at weeks 12 and 24 . Details of the histologic techniques used were published by Headington. ${ }^{23}$ Qualitative evaluation showed that biopsies obtained from individuals receiving either topical minoxidil or placebo did not differ from their pretreatment biopsies with respect to semiquantitative determination of inflammation. There was no suggestion of a direct toxic or irritant effect or of allergic contact dermatitis, nor was epidermal hyperplasia or dysplasia seen. The sebaceous epithelium and papillary reticular dermis appeared unaltered. Morphologic changes were not found in blood vessels, including vessels of the follicular dermal papillae. The seven subjects who received the 5\% dose of minoxidil had a mean hair shaft diameter of $0.029 \mathrm{~mm}$ before treatment, which increased to $0.043 \mathrm{~mm}$ at 12 weeks and measured $0.042 \mathrm{~mm}$ at 24 weeks, although therapy was discontinued after 15.7 weeks. In this study, minoxidil and/or its vehicle affected hair growth by induction or hypertrophy of the existing follicles.

Quantitative data from this study show that we can determine from transverse sections of a scalp biopsy a patient's morphologic capability for response. The identification of potential morphologic nonresponders is, of course, essential to the study of topical stimulation of hair growth.

\section{Comment}

We are continuing an extensive program to evaluate the safety and efficacy of topical minoxidil in certain alopecias. In our studies to date, $1 \%$ and $5 \%$ solutions of topically applied minoxidil induced hair growth in some patients with alopecia areata (totalis, universalis) and alopecia androgenetica. The onset of stimulation of hair growth may be delayed 2-7 months, the stimulated hairs are pigmented, and the increase ranges from minimal to $3 \mathrm{~cm}$ or more. The positive hair growth stimulation seen to date in our studies is quite variable among patients. Some patients who applied topically the higher $(5 \%)$ concentrations of minoxidil to the scalp showed hypertrichosis on the face and extremities, suggesting a systemic side effect.

The mechanism by which minoxidil stimulates hair growth is still unknown. At present, this stimulation

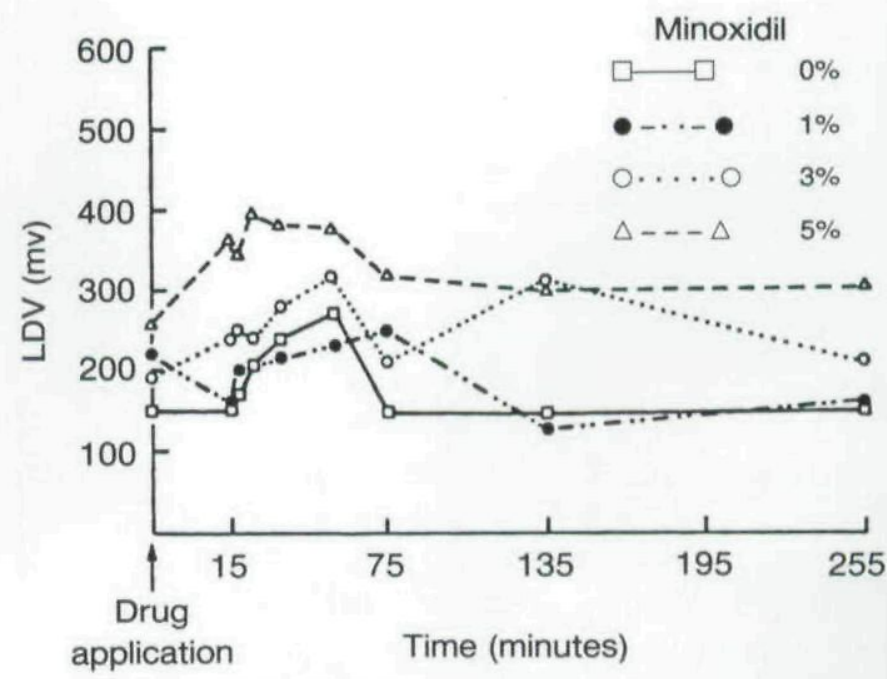

Fic. 1. Mean blood flow-time curve as shown by laser Doppler velocimetry (LDV) following day 1 application of $0 \%, 1 \%, 3 \%$, and $5 \%$ topical minoxidil to bald scalps of four healthy men at each dose.

is attributed to a direct vasodilatory effect of minoxidil on the skin vasculature, but other mechanisms are possible. More basic and clinical research data are needed to assess the potential of topical minoxidil as an agent to stimulate hair growth in patients with alopecia areata and alopecia androgenetica; we are accumulating these data in our ongoing or proposed in vitro (tissue culture), animal, bioavailability, and human studies. Meanwhile, prescription and use of compounded topical minoxidil for alopecias in premature, potentially hazardous, ${ }^{24}$ and not recommended.

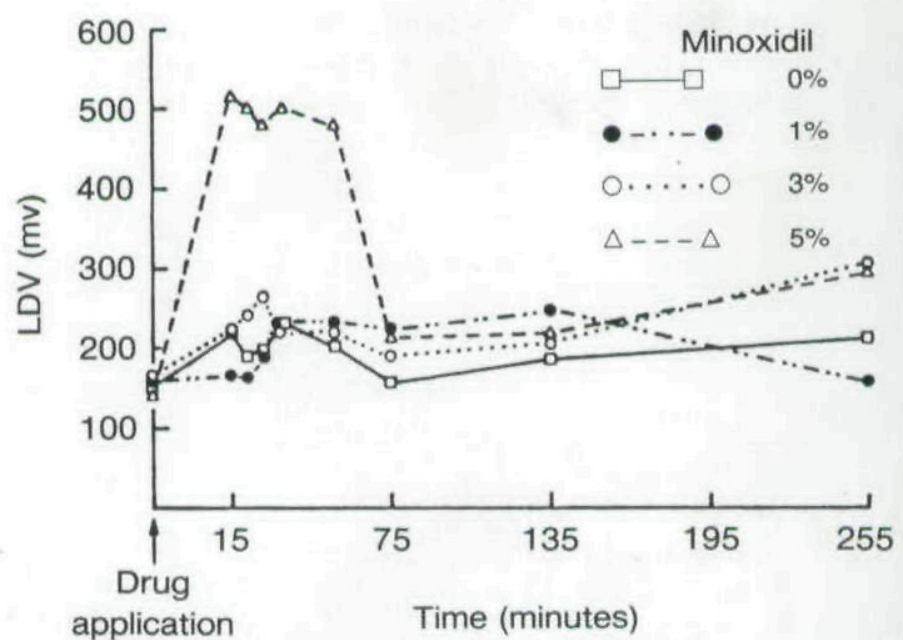

FIG. 2. Mean blood flow-time curve as shown by laser Doppler velocimetry (LDV) following day 2 application of $0 \%, 1 \%, 3 \%$, and $5 \%$ topical minoxidil to bald scalps of four healthy men at each dose. 


\section{Acknowledgment}

Dorothy J. Marshall provided editorial assistance.

\section{Drug Name}

minoxidil: Loniten

\section{References}

1. Chidsey CA, Gottlieb TB. The pharmacologic basis of antihypertensive therapy: the role of vasodilator drugs. Prog Cardiovasc Dis. 1974;27:99-113.

2. Lowenthal DT, Affrime MB. Pharmacology and pharmacokinetics of minoxidil. I Cardiovasc Pharmacol. 1980; 2(suppl):93-106.

3. Gottlieb TB, Thomas RC, Chidsey CA. Pharmacokinetic studies of minoxidil. Clin Pharmacol Ther. 1972;13:436-441.

4. Thomas RC, Hsi RSP, Harpootlian $\mathrm{H}$, et al. Metabolism of minoxidil, a new hypotensive agent. I. Absorption, distribution, and excretion following administration to rats, dogs, and monkeys. J Pharm Sci. 1975;64:1360-1366.

5. Thomas RC, Harpootlian H. Metabolism of minoxidil, a new hypotensive agent. II. Biotransformation following oral administration to rats, dogs, and monkeys. J Pharm Sci. 1975;64:1366-1371.

6. Seidman $M$, Westfried $M$, Maxey $R$, et al. Reversal of male pattern baldness by minoxidil: a case report. Cutis. 1981;28:551-553.

7. Earhart RN, Ball J, Nuss DD, et al. Minoxidil induced hypertrichosis: treatment with calcium thioglycolate depilatory. South Med J. 1977;70:442-445.

8. Zappacosta AR. Reversal of baldness in patient receiving minoxidil for hypertension. N Engl J Med. 1980;303:14801481.

9. Ryan JR, Jain AK, MCMahon FG. Minoxidil treatment of severe hypertension. Curr Ther Res. 1975;17:55-56.
10. Weiss VC, West DP, Mueller CE. Topical minoxidil in alopecia areata. J Am Acad Dermatol. 1981;5:224-226.

11. Fenton DA, Wilkinson JD. Topical minoxidil in the treatment of alopecia areata. Br Med J. 1983;287:1015-1017.

12. Headington JT, Novak E. Clinical and histologic studies of male pattern baldness treated with topical minoxidil. Curr Ther Res. 1984:36:1098-1106.

13. Burton IL, Schutt WH, Caldwell IW. Hypertrichosis due to diazoxide. Br J Dermatol. 1975;93:707-711.

14. Burton IL, Marshall A. Hypertrichosis due to minoxidil. $\mathrm{Br}$ J Dermatol. 1979;101:593-595.

15. Ressmann AC, Butterworth T. Localized acquired hypertrichosis. AMA Arch Dermatol Syphilol. 1952;65:458-463.

16. Eling FJ, Rook A. Hair. In: Rook A, Wilkinson DS, Ebling FJG, eds. Textbook of dermatology. 2nd ed. Oxford: Blackwell Scientific Publications, 1972:1580.

17. Humphrey SJ, Wilson E, Zins GR. Whole body tissue blood flow in conscious dogs treated with minoxidil (abstract.) Fed Proc. 1974:33:583.

18. Holloway GA Jr, Watkins DW. Laser doppler measurement of cutaneous blood flow. I Invest Dermatol. 1977;69:306309.

19. Watkins D, Holloway GA Jr. An instrument to measure cutaneous blood flow using the Doppler shift of laser light. IEEE Trans Biomed Engr. 1978;25:28-33.

20. Guy RH, Maibach, HI, Wester RC. Percutaneous penetration monitored by laser doppler velocimetry. Acad Pharm Sci, abstract \#27, Orlando, 1981.

21. Guy RH, Maibach HI, Wester RC. Non-invasive monitoring of percutaneous absorption in vivo. Clin Res. 1982;30:157A.

22. Wester, RC, Maibach HI, Guy RH, et al. Minoxidil stimulates cutaneous blood flow in human balding scalps: pharmacodynamics measured by laser Doppler velocimetry and photopulse plethysmography. J Invest Dermatol. (in press)

23. Headington JT. Transverse microscopic anatomy of the human scalp: a basis for a morphometric approach to disorders of the hair follicle. Arch Dermatol. 1984;120:449-456.

24. Tkach RJ. Side effects of topical minoxidil treatment of alopecias. Dermatol Allergy. 1983;6:42.

\section{Hay Fever Can Be Dangerous}

During the two-week period of July 22 to August 8, 1982, five people experienced anaphylactic reactions after sustaining skin-abrasion injuries while riding on an Alpine Slide in Vermont. The slide is an amusement ride that consists of a free-running sled that glides down a mountainside on an asbestos-cement track. A case-control study was initiated and included companions of the index cases, noncompanions with abrasion injuries, and six employees who had also had recent abrasion injuries from the slide. Risk factors that were significantly associated with the development of anaphylaxis included abrasions, a personal or family history of allergic complaints, and a history of symptoms of allergic rhinoconjunctivitis at the time of the abrasion injury. A large number of grass-pollen grains and mold spores were identified at the site of the slide, and all four index cases who had skin tests with grass pollens had positive reactions. A review of past records on the index slide and 27 similar amusement slides in the United States revealed 24 additional cases of anaphylactic reactions, 22 of which followed skin abrasions occurring predominantly in late June to early August-the grass-pollination season in the mountains. The evidence, although not conclusive, is consistent with the hypothesis that this syndrome represents systemic anaphylaxis caused by pollen grains introduced into persons who are allergic to grass through skin abrasions sustained while riding the amusement slides.Spitalny KC, Farnham JE, Witherell LE, et al. Alpine slide anaphylaxis. N Engl J Med. 1984;310:1034. 
This document is a scanned copy of a printed document. No warranty is given about the accuracy of the copy. Users should refer to the original published version of the material. 